\title{
Knee arthroplasty in patients with rheumatoid arthritis
}

\author{
B. BLUM,* A. G. MOWAT, G. BENTLEY, AND J. R. MORRIS \\ Rheumatology Unit, Nuffield Departments of Medicine and Orthopaedic Surgery, \\ University of Oxford, Nuffield Orthopaedic Centre, Oxford
}

MacIntosh metallic tibial plateau prostheses have been used in the Nuffield Orthopaedic Centre since 1966 in the knees of patients with rheumatoid arthritis, following the description of the use of these prostheses for the relief of pain and the correction of deformity by MacIntosh (1966). Since that time there have been several reports of the use of these prostheses in both rheumatoid and osteoarthrotic knees (Potter, 1969; McCollum, Goldner, and Lang, 1970; Clary and Couk, 1972; Jessop and Moore, 1972; Kay and Martins, 1972; MacIntosh and Hunter, 1972; Potter, Weinfeld, and Thomas, 1972).

In view of the different indications for and the results of the operation described by these various authors, it seemed valuable to undertake an independent review of the patients treated in this hospital, and to use the results to try and determine the factors which affect the outcome of the procedure, and thereby to define our own indications for the operation.

\section{Patients}

39 patients were reviewed, in fourteen of whom the operation had been performed on both knees. Two patients were lost to follow-up, leaving 51 knees available for assessment. 32 patients with 44 knees had definite rheumatoid arthritis and five patients with seven knees had juvenile rheumatoid arthritis extending into adult life. There were eleven operations on men and forty on women. The age of the patients at the time of surgery ranged from 26 to 73 yrs (average 56). The postoperative follow-up period ranged from $6 \mathrm{mths}$ to 6 years (mean $19.4 \mathrm{mths}$ ).

All patients had undergone a trial of conservative therapy. 23 were receiving corticosteroids, the average daily dose of these drugs being equivalent to $8 \mathrm{mg}$. prednisolone (range 2 to $15 \mathrm{mg}$.) which had been given for a mean of 4 yrs preoperatively. In all cases the same dosage had been maintained postoperatively after the usual brief increase at the time of surgery. A few patients had undergone previous operations on the affected knee; these included synovectomy, proximal tibial osteotomy, patellectomy, and joint debridement.

\section{Indications for surgery}

The decision to perform MacIntosh arthroplasty was based upon the failure of conservative therapy mani fested by unrelievable pain, limitation of function, and deformity. In all cases there was greater articular surface damage than could be expected to be improved by synovectomy. The radiographic appearances were otherwise not important unless there was gross joint collapse or destruction, since there was considerable discrepancy between the radiographic appearances and the findings at operation.

\section{Methods}

\section{METHOD OF REVIEW}

At final review the patients were interviewed and examined by an independent orthopaedic surgeon (B.B.), following a standard protocol* which assessed the technical success of the procedure and stressed functional improvements and difficulties.

The medical records were used to provide preoperative information on the duration of the local and general disease, previous therapy, functional abilities of the patient, examination of the knee, laboratory results, operative technique and findings, and postoperative measurements of joint movement.

Using the immediate preoperative radiographs, measurements were made of genu valgum and varum, and gradings were made of the extent of tibial and femoral condylar damage, the degree of subluxation of the tibia on the femur, and the extent of any patello-femoral arthritis. The same measurements and gradings were made on the postoperative radiographs, and in addition the angle of tilt of the prosthesis with respect to the tibial shaft was measured. It proved impossible to measure bone loss or collapse of the tibial and femoral condyles or settling of the prosthesis reliably. The presence of any posterior tibial buttress was noted.

The data were transferred to punch-cards and a program was prepared for an IBM 1130 computer to record and correlate the information.

OPERATIVE TECHNIQUES

After the application of a pneumatic thigh tourniquet, the joints were opened through medial or lateral parapatellar incisions or both. A synovectomy was performed if the membrane was hypertrophied.

A thin sliver of bone was removed from the tibial plateau, leaving an intact subchondral bone plate as an

* Copies of the protocol available on request. 
horizontal bed in the tibia. A small posterior rim of bone was left in several cases. Care was taken to preserve the tibial spine.

The length of the prosthesis was chosen to fit the size of the tibial plateau and the depth to eliminate collateral ligament laxity. The prosthesis was checked for stability on the tibial plateau through $90^{\circ}$ of joint flexion before wound closure. The patellar tendon was not detached, but in five cases the patella was excised since it was severely involved in the arthritic process. In a few cases trimming of osteophytes and loose fragments of articular cartilage from the femoral condules was performed (Figs 1, 2, 3, and 4).

There was no routine use of suction drainage or antibiotics. Anticoagulants were never employed. The limb was enclosed in a Robert Jones bandage postoperatively.

\section{POSTOPERATIVE CARE}

Isometric quadriceps exercises and knee flexion within the confines of the bandage were encouraged from the first day. The dressing was reduced on the 5th day and sutures were removed on the 14th day. Weight-bearing was permitted as soon as muscle control allowed although, in a few cases in which the tibia was markedly osteoporotic, weight-bearing was restricted for 6 weeks. The mean time from operation on one knee until discharge was 35 days. In seven cases manipulation of the knee under anaesthetic was carried out.

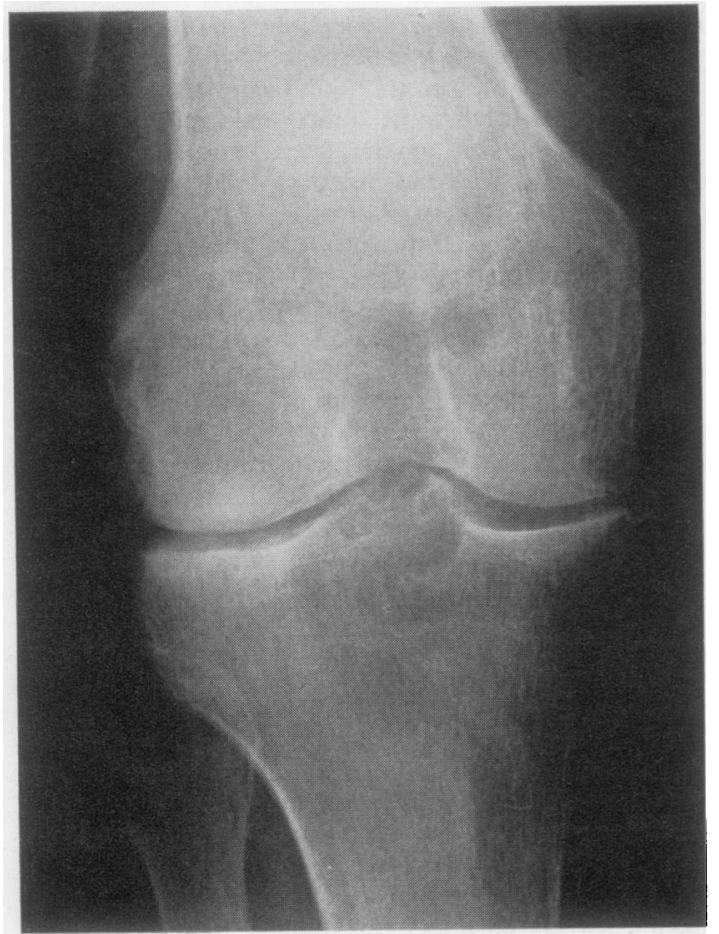

FIGS 1 AND 2 Antero-posterior radiographs, showing the value of standing views in demonstrating the extent of articular cartilage damage and in influencing the decision to perform MacIntosh arthroplasty rather than synovectomy
In four early cases a different technique was employed. The patellar tendon was detached from the tibial tubercle through a curved longitudinal mid-line incision. The bone was removed from the tibial condyles with an electric saw rather than a chisel. The tendon was re-sutured and the knee was held in a semi-rigid dressing until flexion began 6 weeks after operation.

\section{ASSESSMENT OF THE QUALITY OF RESULTS}

On the basis of the final history and examination of the patient, the results were graded as good, fairly good, fair, or poor. The computer was used to determine which criteria were associated with a good result (Table I, opposite).

Again using the computer, it was determined which patients fulfilled these criteria and as expected some of the original good results were excluded and some previously rated fair were included. The criteria for a poor result were similarly determined. Two further, smaller patient groups also emerged from these assessments. Patients rated fairly good had less knee movement but were otherwise identical with good results, whereas patients rated fair had additional unsatisfactory features but were still clearly better than those rated poor (Table I).

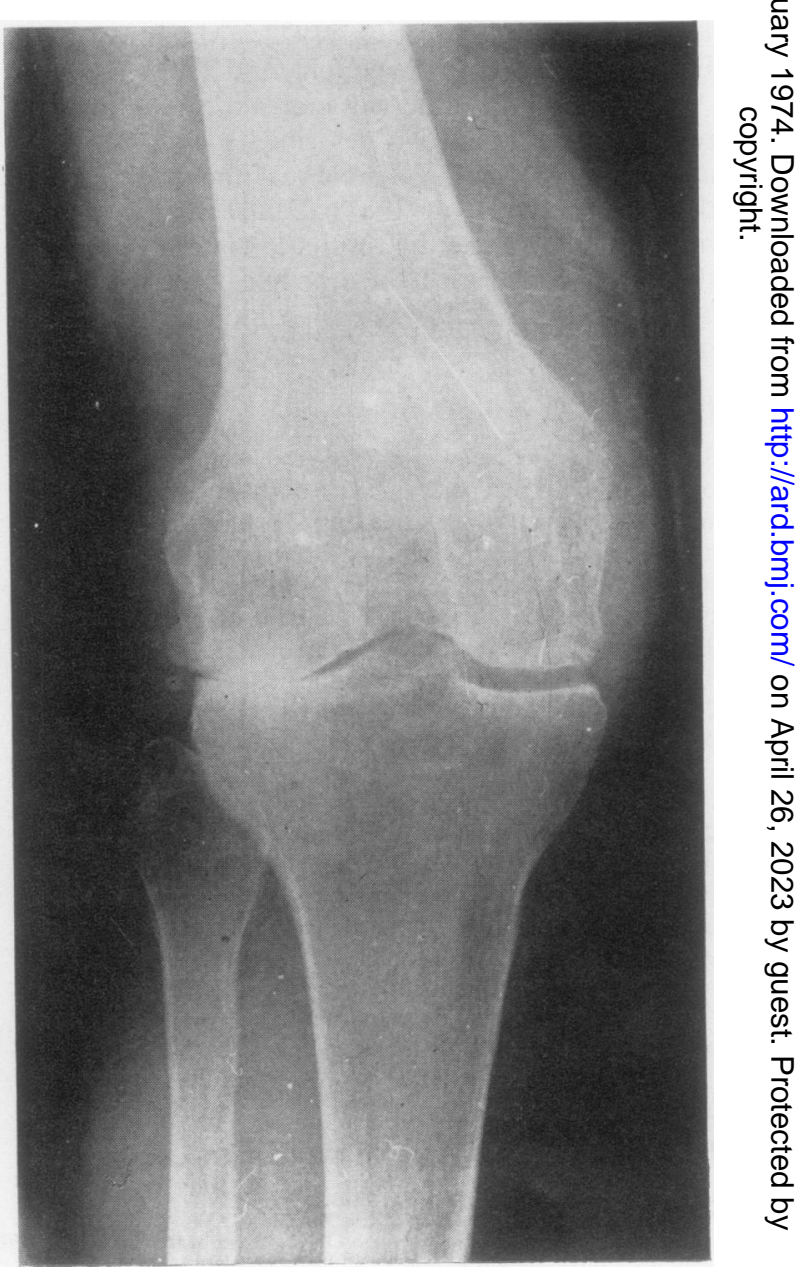


Table I Criteria for assessing results of MacIntosh arthroplasty

\begin{tabular}{|c|c|c|c|c|c|c|}
\hline Result & Pain & $\begin{array}{l}\text { Flexion } \\
\text { deformity }\end{array}$ & $\begin{array}{l}\text { Maximum } \\
\text { flexion }\end{array}$ & $\begin{array}{l}\text { Flexion } \\
\text { arc }\end{array}$ & $\begin{array}{l}\text { Valgus } \\
\text { or varus }\end{array}$ & Functional capacity \\
\hline Good* & $\begin{array}{l}\text { None or slight } \\
\text { No drugs }\end{array}$ & $<20^{\circ}$ & $>80^{\circ}$ & $>60^{\circ}$ & $<10^{\circ}$ & $\begin{array}{l}\text { Normal housework and employment } \\
\text { Walk } 100 \text { metres } \\
\text { One stick } \\
\text { Rise from normal height surfaces }\end{array}$ \\
\hline Fairly good* & Same as good & $<20^{\circ}$ & $>60^{\circ}$ & $>45^{\circ}$ & $<10^{\circ}$ & Same as good \\
\hline Fair* & $\begin{array}{l}\text { Slight or } \\
\text { moderate }\end{array}$ & - & - & $>45^{\circ}$ & - & $\begin{array}{l}\text { Overall improvement } \\
\text { Walk } 50 \text { metres } \\
\text { Two sticks } \\
\text { Rise from chair unassisted }\end{array}$ \\
\hline Poort & Severe & - & $<45^{\circ}$ & - & 一 & No improvement \\
\hline
\end{tabular}

* Result requires fulfilment of all the criteria.

$\dagger$ Result requires fulfilment of only one of the criteria.

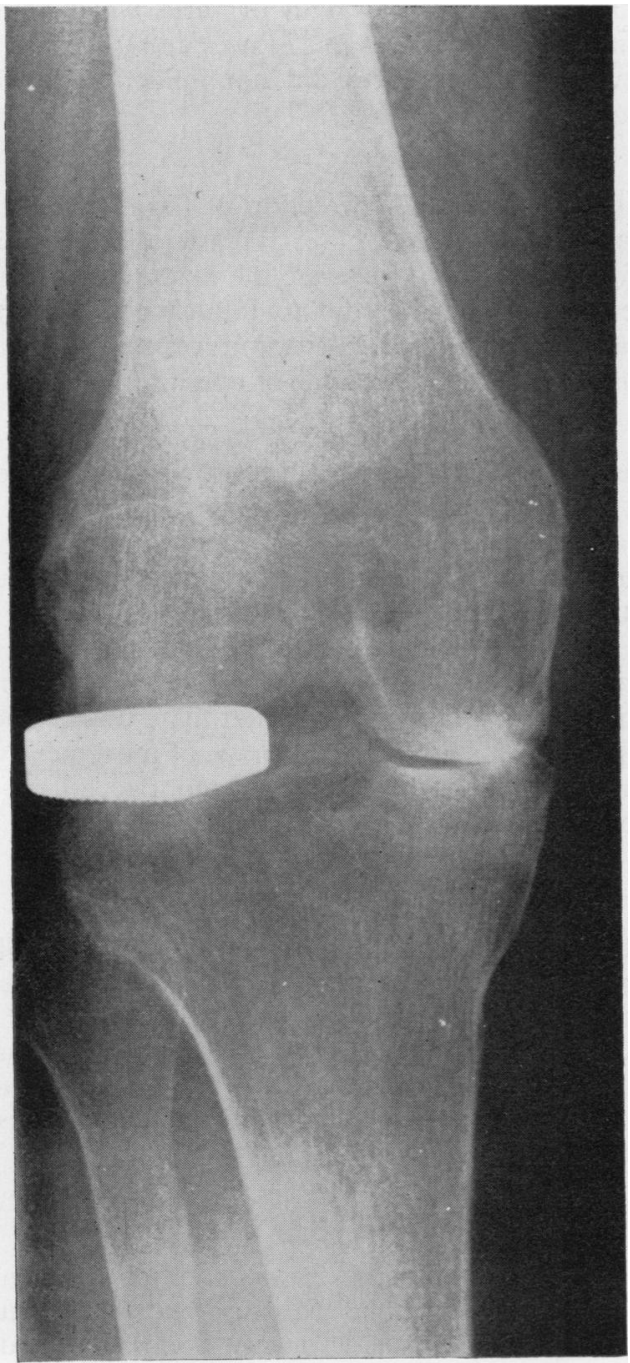

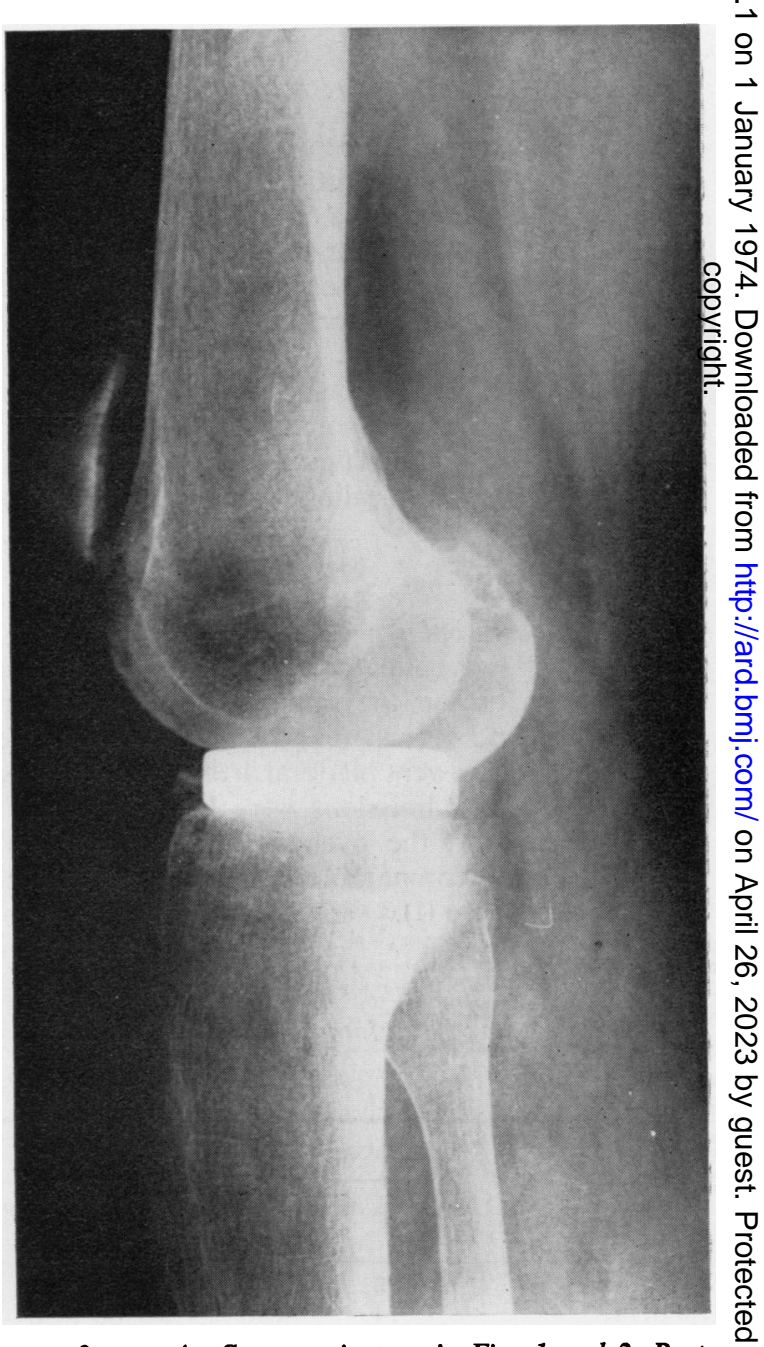

FIGS 3 AND 4 Same patient as in Figs 1 and 2. Postoperative radiographs demonstrating horizontal position of prosthesis and central articulation of femoral condyle 


\section{Results}

In the 51 knees there were 22 good results, five fairly good, seven fair, and seventeen poor.

Using the computer, it was possible to determine some factors which were associated with each type of result. Results will be shown by using the letters G; F-G; F; and P preceded by a number indicating the number of knees with that result.

\section{FACTORS INFLUENCING RESULTS}

\section{(I) Duration of follow-up}

The mean duration (and range) of follow-up was not different for any grade of result. Further, few results changed after discharge from hospital, although four knees graded poor had fair results for intervals of 3 months, 3 months, 1 year, and 2 years.

\section{(2) General conditions}

There was no correlation between haemoglobin level and erythrocyte sedimentation rate and the final result, nor did the presence of rheumatoid factor or its titre in the serum correlate with the results. Similarly, there was no correlation between the duration of the general or local disease and the results.

The quality of the final result was unrelated to the dosage or duration of corticosteroid therapy. In particular, there was no higher incidence of wound infection or delayed healing in patients receiving these drugs.

\section{(3) Bilateral arthroplasty}

The results in five patients who underwent bilateral arthroplasties during the same hospital admission were $3 \mathrm{G}, 3 \mathrm{~F}$, and $4 \mathrm{P}$, whereas the results in the nine patients who underwent bilateral arthroplasty during separate hospital admissions were 11G, 1F-G, 2F, and 4P. However, the overall results of bilateral arthroplasty were comparable with those of unilateral arthroplasty (Table II).

Table II Result of MacIntosh arthroplasty in 51 knees

\begin{tabular}{|c|c|c|c|c|}
\hline \multirow{2}{*}{$\begin{array}{l}\text { Surgical } \\
\text { procedure }\end{array}$} & \multicolumn{4}{|l|}{ Result } \\
\hline & Good & $\begin{array}{l}\text { Fairly } \\
\text { good }\end{array}$ & Fair & Poor \\
\hline $\begin{array}{l}\text { Unilateral } \\
\text { Bilateral } \\
\text { Bicompartmental } \\
\text { Medial } \\
\text { Lateral }\end{array}$ & $\begin{array}{r}8 \\
14 \\
3 \\
5 \\
14\end{array}$ & $\begin{array}{l}4 \\
1 \\
2 \\
1 \\
2\end{array}$ & $\begin{array}{l}2 \\
5 \\
2 \\
2 \\
3\end{array}$ & $\begin{array}{r}9 \\
8 \\
11 \\
1 \\
5\end{array}$ \\
\hline
\end{tabular}

\section{(4) Other surgical procedures}

(a) Synovectomy

Although synovectomy was undertaken as a preliminary to the arthroplasty if the membrane was hypertrophied, mild recurrence of synovial proliferation and effusion did not influence the results. The results of $5 \mathrm{G}$ and $1 \mathrm{~F}$ in six patients who had undergone previous synovectomy were better than average.

\section{(b) Contralateral stiff knee}

Arthroplasties undertaken in three patients with previous contralateral knee arthrodeses led to poor results.

\section{(5) Preoperative state}

(a) Ligamentous laxity

Medial and lateral collateral and anterior cruciate ligamentous laxity bore no relationship to the final result. The degree of valgus or varus which ranged from 3 to $30^{\circ}$ of valgus in 27 knees and from 3 to $20^{\circ}$ of varus in four knees did not influence the final result.

\section{(b) Flexion deformity}

In most cases some correction of flexion deformity was made with the use of serial plaster of Paris splints before operation. However, the extent of this final fixed flexion deformity did not influence the operative result, since further correction of the deformity usually occurred at the time of operation.

\section{(c) Range of movement}

The range of preoperative flexion was $80^{\circ}$ or more, the range accepted as a criteria for a good result, in all but five cases. This range did not appear to influence the final result. There were as many good results as bad for each flexion range over $80^{\circ}$. In the patients with a good result the operation did not significantly alter the range of flexion, whereas in all patients with a fair or poor result there was a serious loss of movement. The final range of movement was achieved at approximately 2 months' after the operation.

\section{(6) Patellectomy}

In five knees which had undergone previous patellectomy the results were $1 \mathrm{G}, 2 \mathrm{~F}$, and $2 \mathrm{P}$, whereas in five knees with concomitant patellectomy the results were $2 \mathrm{G}, 1 \mathrm{~F}-\mathrm{G}$, and $2 \mathrm{P}$. The latter results were very similar to those of the whole series. Patellectomy was not associated with quadriceps muscle weakness.

\section{(7) Size of prostheses (Fig. 5)}

The size of the prostheses was carefully chosen to suit the size of the tibial plateau, to correct as much of the valgus or varus deformity as possible, and to 


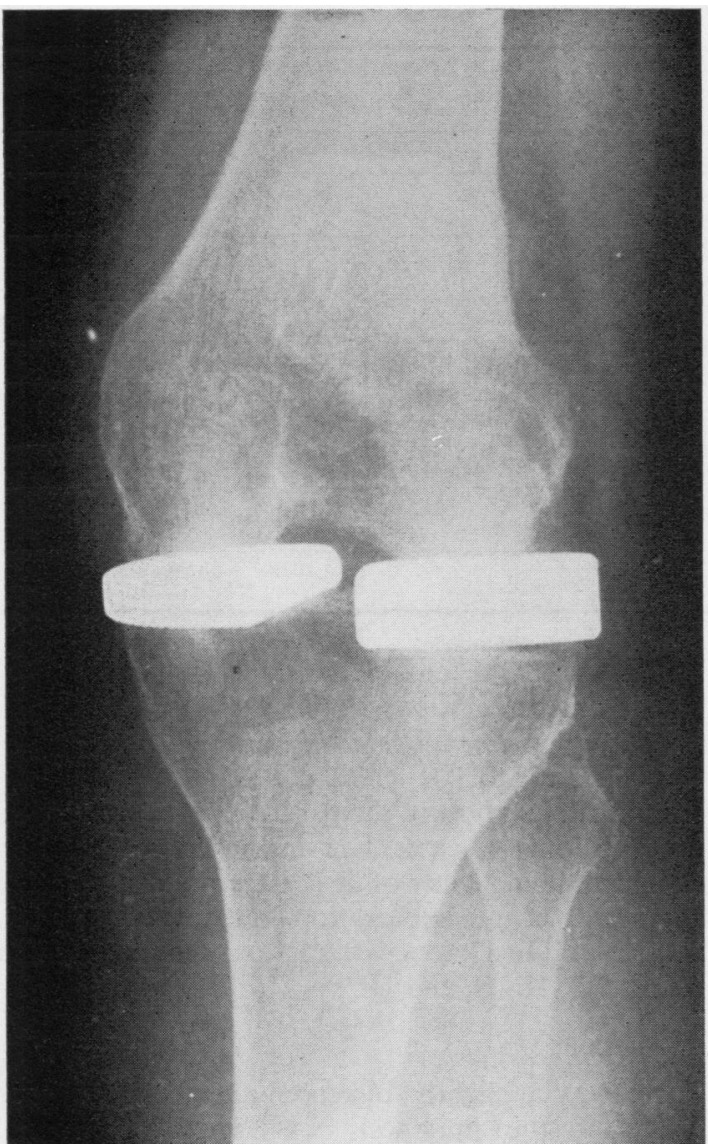

FIG. 5 Antero-posterior radiograph. There is a $2 S$ prosthesis in the lateral compartment and a $1 S$ in the medial compartment to correct valgus deformity in a knee with advanced bicompartmental damage

reduce ligamentous and capsular laxity. To some extent this practice appears to have been beneficial, since less than $10^{\circ}$ of valgus or varus postoperatively was required to produce a good result. However, there was no correlation between pre- and postoperative ligamentous and capsular laxity and the final results.

(8) Unicompartmental and bicompartmental prostheses A single compartment prosthesis was associated with better results than bicompartmental prostheses (Tables II and III). In particular, it was associated with more motion, less lateral deformity, and more capsular laxity. Lateral prostheses alone were used more frequently than medial prostheses alone but the results were similar. In Table IV (overleaf) the extent of the disease in the medial and lateral compartments of the knees based upon the pre-operative radiographs is compared with the results obtained with the unior bicompartmental prostheses. Unicompartmental disease occurred only in the lateral compartment and was treated with a lateral prosthesis in all but one case. In the presence of disease in both compartments, better results were achieved with a single prosthesis whatever the extent of the disease. Detailed analysis of the eleven knees which had a poor result when treated for bicompartmental disease with both medial and lateral prostheses did not reveal anye factors which would explain these findings completely

\section{(9) Manipulation under anaesthesia}

This was performed on seven knees because of delayed return of motion. In four the procedure led to an increased range of motion with final results of $3 \mathrm{G}$ and 1F-G. However, in two knees the motion failed to increase and one patient sustained a supracondylar fracture of the femur. These three knees had a poor result.

\section{(10) Different operation technique}

In the four patients in whom mobilization was delayed for 6 weeks the final results were $1 \mathrm{G}, 1 \mathrm{~F}-\mathrm{G}$, $1 \mathrm{~F}$, and $1 \mathrm{P}$.

Table III Results with unicompartmental and bicompartmental prostheses

\begin{tabular}{|c|c|c|c|c|c|}
\hline \multirow[t]{2}{*}{ Prosthesis } & \multicolumn{4}{|l|}{ Result } & \multirow[t]{2}{*}{ Radiographic damage } \\
\hline & Good & Fairly good & Fair & Poor & \\
\hline $\begin{array}{l}\text { Bicompartmental } \\
\text { Medial } \\
\text { Lateral }\end{array}$ & $\begin{array}{l}3 \\
3 \\
9\end{array}$ & $\begin{array}{r}-1 \\
2\end{array}$ & $\begin{array}{l}1 \\
2 \\
1\end{array}$ & $\begin{array}{r}11 \\
1 \\
2\end{array}$ & Bicompartmental \\
\hline $\begin{array}{l}\text { Bicompartmental } \\
\text { Lateral }\end{array}$ & $\overline{5}$ & - & $\begin{array}{l}1 \\
2\end{array}$ & $\overline{3}$ & Lateral compartment \\
\hline $\begin{array}{l}\text { Bicompartmental } \\
\text { Medial }\end{array}$ & $\overline{2}$ & $\underline{2}$ & - & - & Radiographs lost \\
\hline
\end{tabular}


Table IV Comparative criteria for a 'good' result of MacIntosh arthroplasty

\begin{tabular}{|c|c|c|c|c|c|c|c|c|c|c|c|c|}
\hline Series & Date & Pain & $\begin{array}{l}\text { Fixed } \\
\text { flexion }\end{array}$ & $\begin{array}{l}\text { Maximum } \\
\text { flexion }\end{array}$ & $\begin{array}{l}\text { Flexion } \\
\text { arc }\end{array}$ & Varus & Valgus & Stability & $\begin{array}{l}\text { Quadri- } \\
\text { ceps } \\
\text { strength }\end{array}$ & Support & Function & Radiograph \\
\hline Clary and Couk & 1972 & Relief & $<10^{\circ}$ & $>70^{\circ}$ & & & & Good & & None & Improved & \\
\hline $\begin{array}{l}\text { Henderson and } \\
\text { Peterson }\end{array}$ & 1969 & Relief & $<10^{\circ}$ & Improved I & Improved & & & Improved & & None & Improved & \\
\hline $\begin{array}{l}\text { Jessop and } \\
\text { Moore }\end{array}$ & 1972 & Relief & $<10^{\circ}$ & $>70^{\circ}$ & & $<10^{\circ}$ & $<10^{\circ}$ & & & & & \\
\hline Kay and Martins & 1972 & Relief & & & $>75^{\circ}$ & & & Good & & & & Satisfactory \\
\hline Lowe and others & 1971 & Pain free & $<10^{\circ}$ & & $>90^{\circ}$ & & & Stable & & & & \\
\hline $\begin{array}{l}\text { Macintosh and } \\
\text { Hunter }\end{array}$ & 1972 & Relief & $<20^{\circ}$ & & $>60^{\circ}$ & $<5^{\circ}$ & $<10^{\circ}$ & Stable & Strong & 1 stick & Improved & \\
\hline Murray & 1967 & Relief & & & Increase & Corr & ion & & & & Restored & \\
\hline $\begin{array}{c}\text { Potter and } \\
\text { others* }\end{array}$ & $\overline{1972}$ & $\begin{array}{c}\text { None or } \\
\text { slight }\end{array}$ & $<5-15^{\circ}$ & $>60-80^{\circ}$ & & $<10^{\circ}$ & $<10^{\circ}$ & $\begin{array}{l}10^{\circ} \\
\text { wobble }\end{array}$ & Normal & 1 stick & & \\
\hline Present series & & $\begin{array}{l}\text { None or } \\
\text { slight }\end{array}$ & $<20^{\circ}$ & $>80^{\circ}$ & $>60^{\circ}$ & $<10^{\circ}$ & $<10^{\circ}$ & & & 1 stick & $\begin{array}{l}\text { Normal ho } \\
\text { and emp }\end{array}$ & $\begin{array}{l}\text { ousework } \\
\text { ployment }\end{array}$ \\
\hline
\end{tabular}

* A point scale was used in which a bad value in one column could outweigh a good value in another.

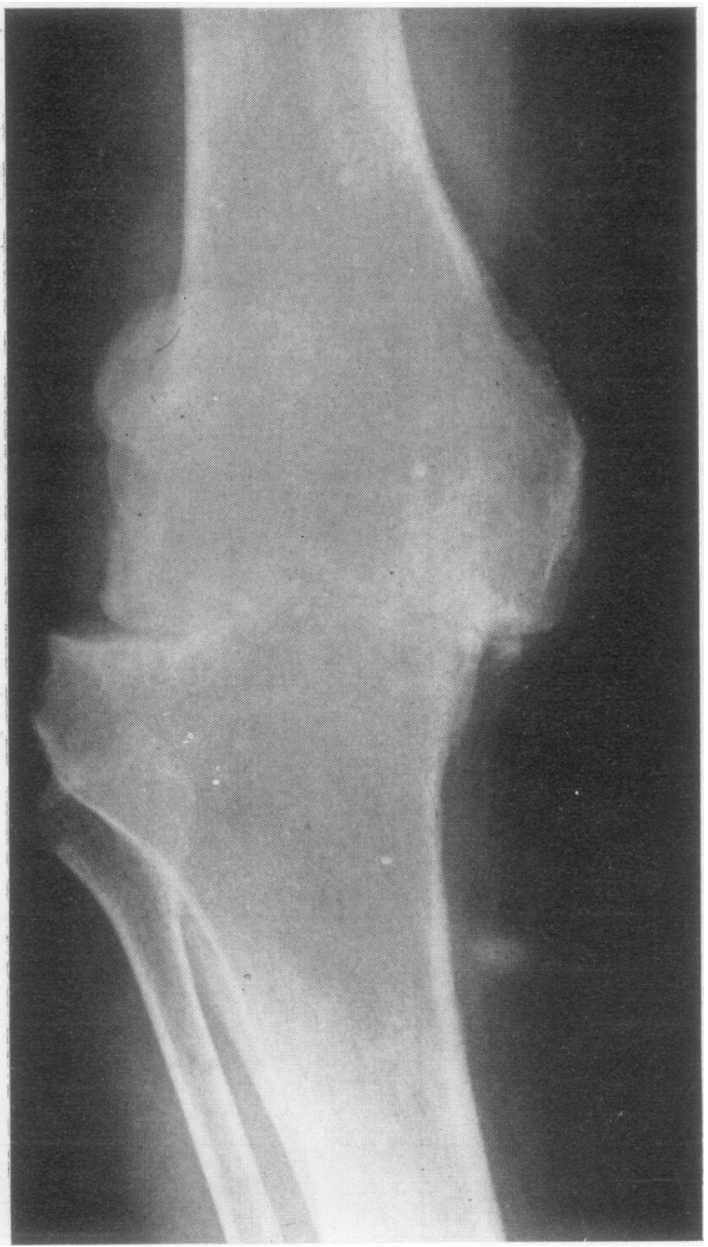

FIG. 6 Antero-posterior radiograph of a patient with gross lateral subluxation of the tibia and varus deformity

\section{RADIOGRAPHIC ANALYSIS}

(1) Unicompartmental and bicompartmental disease (Figs 6, 7, and 8)

Lateral subluxation of the tibia upon the femur was noted in fourteen cases, but was not associated with an increased incidence of unsatisfactory results. Nine knees with slight subluxation had results $2 \mathrm{G}, 2 \mathrm{~F}$, and 5P, and five knees with marked subluxation had results $3 G, 1 F-G$, and $1 P$.

\section{(2) Tilt of prosthesis}

There was a slightly increased incidence of poor results if the prosthesis was tilted posteriorly. However, medial or lateral tilt of the prosthesis of up to $20^{\circ}$ was not associated with adverse results. A posterior bony buttress was associated with rather more poor results.

\section{COMPLICATIONS}

There were fifteen complications in fourteen knees.

Six wound edges gaped, leading to delayed wound healing; these knees were associated with average results for the series.

There were three superficial wound infections, but it was not necessary to remove a prosthesis because of infection.

One patient had a serious skin slough necessitating skin grafting and in addition had foot drop due to damage to the lateral popliteal nerve; skin integrity and foot function was restored but the knee was a poor result.

Another patient had a mild foot drop, but with full prompt recovery.

One prosthesis dislocated anteriorly and despite re-operation the result was poor.

One patient sustained a supracondylar fracture of the femur during manipulation under anaesthesia.

One patient had a minor pulmonary embolism. 


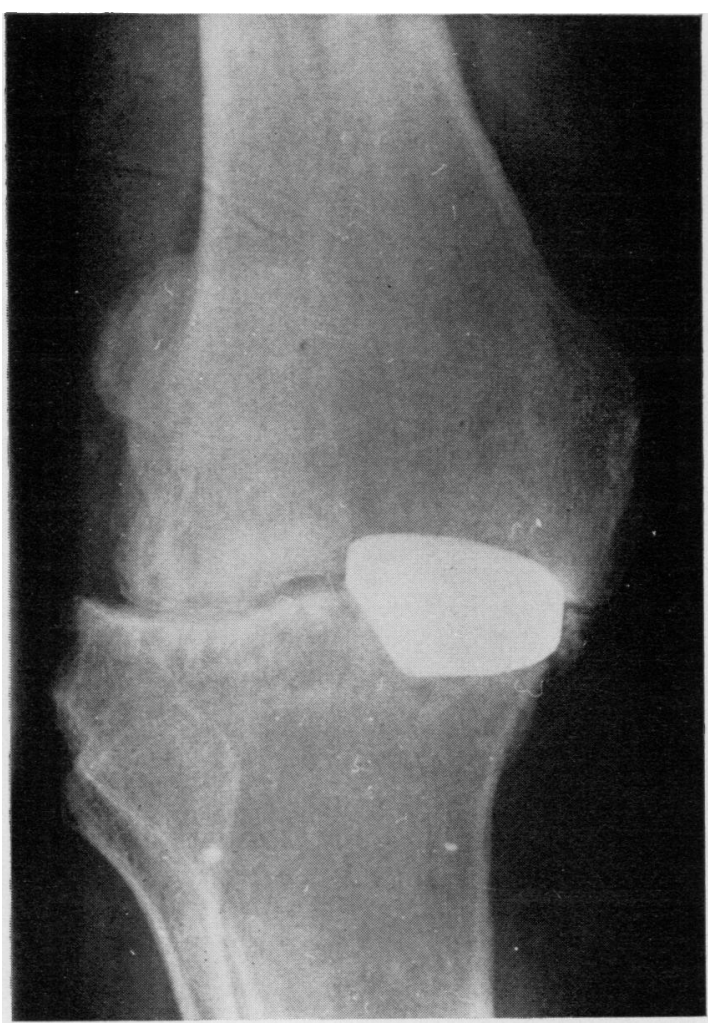

FIGS 7 AND 8 Same patient as in Fig. 6. Radiographs after insertion of a medial MacIntosh prosthesis. Despite persistent subluxation of the knee and poor positioning of the prosthesis the patient had a good result 4 years postoperatively

\section{Discussion}

There remains considerable debate about the indications for and the merits of the various arthroplasties that have been used in the rheumatoid knee The history of development of these arthroplasties has been reported by Jessop and Moore (1972), and Potter and others (1972) and MacIntosh and Hunter (1972) have described the development of the MacIntosh arthroplasty. This form of knee arthroplasty is the most popular of the non-hinge type, although Potter and others (1972) have achieved similar results with both MacIntosh and McKeever tibial plateau prostheses.

Comparison of the results achieved in patients with rheumatoid arthritis with the MacIntosh arthroplasty by different surgical groups is difficult since different methods of assessment have been used by each group (Tables IV and V). Further, not all reports have included sufficient details of the methods of assessment to permit their proper use. This is unfortunate, since it means that direct comparison of results is

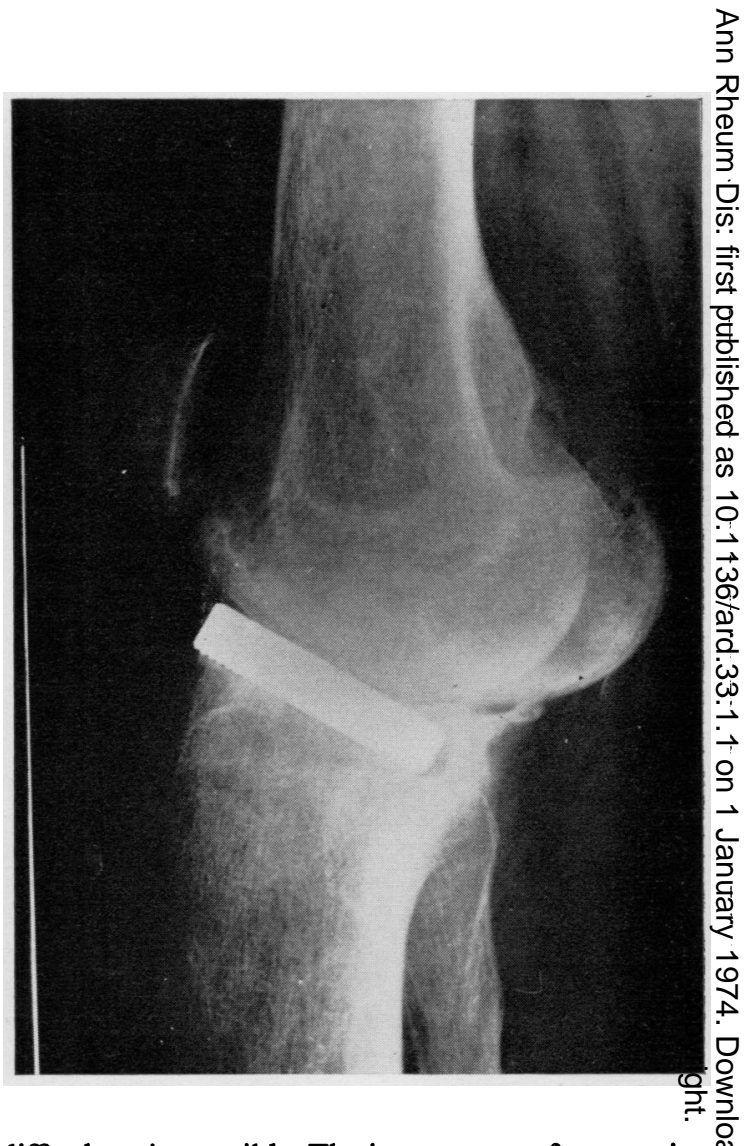

difficult or impossible. The importance of comparing various methods of measurement has recently been $\stackrel{\curvearrowright}{\propto}$ demonstrated by Anderson (1972) who employed $\overrightarrow{\vec{F}}$ nine different methods of assessment on patients 3 who had undergone hip surgery and found the percentage of good results varied from 97.5 to 30 per cent.

Our method of assessment, in common with some others (Potter and others, 1972; Jessop and Moore, $\overline{7}$ 1972), included assessment of the patient's functional:capacity and indicated the patient's degree of satis- 0 faction with the procedure. This compares with other methods which appear to measure chiefly or solely응 the technical success of the procedure (Kay and $>$ Martins, 1972; MacIntosh and Hunter, 1972) and을. which may also fail to record the patient's opinion of the procedure for fear of biased results due to the patient's loyalty to his surgeon (MacIntosh and $\tilde{O}^{\circ}$ Hunter, 1972). We, like others, used an independent $\stackrel{\sim}{\omega}$ assessor to overcome the possible enthusiasm of the surgeon for the procedure.

The operative technique and postoperative manage $-\frac{\mathbb{}}{\AA}$ ment described in this paper are similar to those used $\stackrel{\oplus}{+}$ by other authors. However, it seems that con- $-\frac{T}{0}$ siderable differences in management achieve similar results. Thus McCollum and others (1970) and Murray (1967) delayed full weight-bearing for $6 \stackrel{\circ}{\circ}$ weeks and 3 months' respectively, and Murray (1967)우 
Table V Comparative results of MacIntosh arthroplasty in patients with rheumatoid arthritis

\begin{tabular}{|c|c|c|c|c|c|c|c|c|c|c|c|c|c|c|c|c|c|c|}
\hline \multirow[t]{2}{*}{ Series } & \multirow{2}{*}{ Date } & \multirow{2}{*}{$\begin{array}{l}\text { Number } \\
\text { of } \\
\text { knees }\end{array}$} & \multicolumn{2}{|c|}{ Excellent } & \multicolumn{2}{|c|}{ Good } & \multicolumn{2}{|c|}{ Successful } & \multicolumn{2}{|c|}{ Fairly good } & \multicolumn{2}{|c|}{ Satisfactory } & \multicolumn{2}{|c|}{ Fair } & \multicolumn{2}{|c|}{ Poor } & \multicolumn{2}{|c|}{ Failure } \\
\hline & & & No. & Per cent. & No. & Per cent. & No. & Per cent. & No. & Per cent & No. & Per cent. & No. & Per cent. & No. & Per cent. & No. & Per cent. \\
\hline Clary and Couk & 1972 & 26 & 8 & 31 & 7 & 27 & & & & & & & 8 & 31 & & & 3 & 11 \\
\hline $\begin{array}{l}\text { Henderson and } \\
\text { Peterson }\end{array}$ & $\overline{1969}$ & 21 & & & $\overline{6}$ & 29 & & & & & & & 4 & 19 & 11 & 52 & & \\
\hline $\begin{array}{l}\text { Jessop and } \\
\text { Moore }\end{array}$ & 1972 & 28 & $\overline{12}$ & $42 \cdot 8$ & & & & & & & & & $\overline{4}$ & $14 \cdot 4$ & 12 & $42 \cdot 8$ & & \\
\hline Kay and Martins & $\overline{1972}$ & 40 & & & 19 & $47 \cdot 5$ & & & & & 10 & 25 & & & 11 & $27 \cdot 5$ & & \\
\hline Lowe and others & 1972 & 83 & & & & & 52 & $62 \cdot 6$ & & & 17 & 20 & & & & & 14 & $17 \cdot 4$ \\
\hline $\begin{array}{l}\text { MacIntosh and } \\
\text { Hunter }\end{array}$ & $\overline{1972}$ & 89 & & & $\overline{61}$ & $68 \cdot 5$ & & & & & & & & & $\overline{24}$ & 27 & 4 & 4.5 \\
\hline Murray & 1967 & 20 & 10 & 50 & 6 & 30 & & & & & & & 2 & 10 & 2 & 10 & & \\
\hline $\begin{array}{l}\text { Potter and } \\
\text { others }\end{array}$ & $\overline{1972}$ & 99 & $\overline{36}$ & $36 \cdot 3$ & $\overline{20}$ & $20 \cdot 2$ & & & & & & & $\overline{16}$ & $16 \cdot 2$ & $\overline{27}$ & $\overline{27 \cdot 3}$ & & \\
\hline Present series & & 51 & & & 22 & 43 & & & 5 & 10 & & & 7 & $13 \cdot 5$ & $\overline{17}$ & 33.5 & & \\
\hline
\end{tabular}

manipulated all knees approximately 3 weeks after the operation. Other authors have employed manipulation for selected knees showing a slower than average return of movement and, as in our seven cases, the final results do not appear to differ from the series as a whole (Potter, 1969; MacIntosh and Hunter, 1972). It may be important carefully to remove the posterior cortical rim of bone, since we noted poorer results in those cases with posterior buttresses to the prosthesis, although it must be admitted that rotational effects in the lateral radiographs make the identification of a true buttress difficult.

Lowe, Kates, and Kay (1971) have recommended the use of methyl methacrylate bone cement in conjunction with slightly altered undersurfaces of the prostheses to aid in fixation. This was associated with an increase from 47 to 71 per cent. in successful cases.

There was no correlation between the activity of the local or general rheumatoid disease, the duration of the disease, the presence of rheumatoid factor in the serum, or the use of corticosteroid therapy and the final results. Lowe and others (1971) have reported similar findings. Further, there was no evidence that corticosteroid therapy impaired wound healing (Garner, Mowat, and Hazleman, 1973).

Patients who underwent arthroplasties on both knees during separate hospital admissions achieved better results than those in whom bilateral arthroplasties were performed during a single admission. This may reflect difficulties in mobilizing both knees together. Further, the poor results in three patients who had had contralateral knee arthrodeses may also reflect difficulties in encouraging joint flexion and normal ambulation.

Insertion of a MacIntosh tibial plateau prosthesis often reduces or eliminates considerable flexion and angular deformity. Most authors consider that up to $30^{\circ}$ flexion deformity and up to $20^{\circ}$ varus deformity can be eliminated by appropriate surgical techniques and the selection of suitable prostheses. Our results confirm these findings, but it must be stressed that complete correction of these deformities is not necessary to achieve satisfactory results. Lowe and others (1971) found that better results were achieved in those knees with moderate preoperative laxity; less satisfactory results being found in very lax or tight knees. Our results did not support these findings; similar results being found with all degrees of ligamentous laxity.

There is reluctance to combine patellectomy with the MacIntosh arthroplasty in the belief that the results will be poorer and mobilization delayed. We found no difference in the results in patients who had had previous patellectomy, no patellectomy, or concomitant patellectomy. Similarly MacIntosh and Hunter (1972), although advising against concomitant patellectomy, found seven good results in twelve knees. Nevertheless, we remove the patella only if there are specific patello-femoral symptoms.

MacIntosh and Hunter (1972) emphasized that, although they use radiographs including a standing view, arthroscopy, and arthrography in an attempt to determine the degree of damage in the medial and lateral joint compartments, a decision on the need for uni- or bicompartmental prostheses must be made at the time of the operation. This was also our policy, but it was often found that adequate correction of deformity and restoration of function could be achieved by the use of a single prosthesis even in the face of severe bicompartmental damage. Our results show that in these circumstances unicompartmental surgery achieved better results than bicompartmental surgery. Detailed analysis of the eleven poor results of bicompartmental surgery did not reveal any factors which could explain these findings. It is possible that the insertion of two prostheses into an 
extensively damaged joint produces a poorer biomechanical situation than when one prosthesis is used. Our findings are in agreement with those of Kay and Martins (1972), although the results have been interpreted differently. These authors stated that unicompartmental surgery produced poorer results, but their figures show that twelve of fifteen knees so treated had relief of pain compared with 22 of 29 knees treated with bicompartmental surgery. Similarly nine of the fifteen knees showed an increase in motion, while a further three showed no change and three showed a decrease in motion. The comparative figures for motion for the 24 knees treated with bicompartmental surgery in which motion was measured were six, nine, and eight, and one knee was ankylosed. Jessop and Moore (1972) found good results in four of ten (40 per cent.) unicompartmental operations and eight of eighteen ( 44 per cent.) bicompartmental operations. Although MacIntosh and Hunter (1972) used mostly bicompartmental surgery and Clary and Couk (1972) mostly unicompartmental surgery, the results do not favour either operative procedure.

Although it appears important to provide a satisfactory bed for the prosthesis, we found that up to $20^{\circ}$ of tilt of the prosthesis was not associated with poorer results. Similarly, Lowe and others (1971) found that, although sloping of both prostheses in a medial or lateral direction could be associated with subluxation, there could, otherwise, be a wide variation in the positioning of the prostheses without change in results. Poor results may be associated with abnormal settling of the prosthesis, since the correction for depth is no longer accurate. Measurement of this from postoperative radiographs proved unreliable.

Our complications are very similar in type and frequency to those noted by other authors. Problems of wound healing, skin sloughing, and foot drop may arise from over-distraction of tissues. We incurred fewer complications when two incisions were used during bicompartmental surgery. The prosthesis dislocation occurred anteriorly in an over-weight male during the first week of full knee flexion. The prosthesis was re-sited without difficulty and although it has remained in good position the final result has been poor. Deep infection, necessitating removal of the prosthesis, is uncommon. It is worth noting that the operation causes little permanent alteration to the structures in and around the knee joint and does not jeopardize further surgical procedures.

It should be possible, after reviewing the results of any form of therapy, to identify a group of patients who will benefit from such therapy. This has proved difficult with the MacIntosh arthroplasty in patients with rheumatoid arthritis. There is general agreement that the operation should not be undertaken in the extensively damaged joint from whatever cause. $\frac{\stackrel{2}{3}}{3}$ However, it may be difficult to define or measure the extent of the damage. Kay and Martins (1972) suggested that significant damage should be confined to $\vec{\Rightarrow}$ the tibial condyles and that the destruction should $\stackrel{5}{+}$ not exceed $5 \mathrm{~mm}$. in depth. We found measurements of this destruction on preoperative radiographs unreproducible. The operation is rather more successful in patients with osteoarthrosis (MacIntosh $\stackrel{\mathbb{2}}{2}$ and Hunter, 1972; McCollum and others, 1970; Clary and Couk, 1972; Potter and others, 1972), $\vec{\circ}$ and has a limited place in the management of tibial condyle fracture (Crellin, 1965). However, it is clear $\vec{\omega}$ that marked local and general rheumatoid disease, a wide range of knee deformities, concomitant patellectomy, subsequent manipulation, bilateral $\underset{\omega}{\omega}$ operations, and previous knee surgery are not bars to successful results in well motivated patients. In our hands uniformly poor results occurred only in 음 patients with arthrodesis of the contralateral knee. $\vec{c}$ Similarly, in many of the cases with poor results, it was not possible to determine the factors which led to these results. Other authors have clearly had the same difficulties in interpreting their results and it $\overrightarrow{0}$ does not therefore seem wise to produce a list of criteria which make the knee joint unsuitable for MacIntosh arthroplasty if as many as 56 per cent. of the patients may be deprived of a good or satiso factory result (Kay and Martins, 1972).

\section{Summary}

(1) The results of MacIntosh arthroplasty in 51 knees in patients with rheumatoid arthritis have been assessed by an independent observer.

(2) Good results associated with the ability to undertake normal housework and employment were found in 22 knees ( 43 per cent.); fairly good results associated with similar function but less knee motion in five knees (10 per cent.); fair results associated with some functional improvement and reduction of pain in seven knees (13.5 $\frac{D}{2}$ per cent.); and poor results associated with severe pain or poor motion or no functional $N$ improvement in seventeen knees $(33.5$ per $N$ cent.).

(3) Severe bicompartmental joint damage and arthrodesis of the contralateral knee were associated with poor results, and are probably $\stackrel{\circ}{\subseteq}$ contraindications for the operation.

(4) Better results were achieved with the use of a single prosthesis than with two prostheses even in the presence of serious bicompartmental joint $\frac{\pi}{\mathbb{D}}$ damage. The reasons for this finding are largely $\frac{\Omega}{\mathbb{D}}$ unexplained.

(5) The severity of the general rheumatoid disease, the duration of the local and general disease, the 
presence of rheumatoid factor in the serum, and the use of corticosteroids did not affect the result.

(6) Ligamentous laxity and preoperative valgus deformity of $30^{\circ}$, varus deformity of $20^{\circ}$, and flexion deformity of $30^{\circ}$ were consistent with good results.

(7) Patellectomy, moderate tilt of the prosthesis, and varying methods of postoperative management did not influence the results.

(8) It is concluded that the MacIntosh arthroplasty can reduce pain and improve function in a wide range of rheumatoid knees, and that it is difficult to list definite indications and contraindications for the operation.

We wish to thank Prof. R. B. Duthie and members of his team who undertook the surgical treatment of the majority of the patients. We are most grateful to Mr. J. W. Goodfellow for allowing us to include five of his patients in this study. We also extend our thanks to Mr. R. Emmanuel for the photographs and Mrs. M. Evans for typing the paper.

Dr. Alastair G. Mowat is in receipt of a grant from the Arthritis and Rheumatism Council.

\section{DISCUSSION}

DR. A. G. S. HILL (Stoke Mandeville) I speak with some diffidence because what $I$ have to say is based on a very recently concluded survey of only 22 patients. But first of all I must congratulate Dr. Mowat and his group on their critical approach to the evaluation of a surgical procedure which we so badly need. We differ slightly, though our numbers are small, eleven were unicompartmental and eleven bicompartmental procedures. Although the differences cannot be statistically significant, our results to date favour the bicompartmental operation. One question we asked the patients, which is something we took from the U.K. synovectomy trial, was, 'given your time over again would you have the same thing done?' The patients may have tried to be kind to their surgeons but, for what its worth, twenty of the 22 patients said 'yes' they would have it done again. The two who said 'no' were unicompartmental cases. Dr. Mowat said the duration of follow-up had no bearing on the outcome and our findings for recovery of movement after the operation are shown in Figs $A$ and $B$. This is the total range of flexion, and the range pre-operatively is put at $\mathbf{1 0 0}$ per cent, so that all the patients start at 100 per cent. The horizontal scale is in months and from 3 months onwards, even 5 from months onwards, there was still quite an improvement in range in patients with the lines approaching the 100 per cent. level. So I think that, as after synovectomy, one can afford to be fairly optimistic, even though the initial rate of improvement is perhaps a little disappointing. We use charts of this nature in synovectomy cases to discourage people from doing manipulations, and the purpose of this chart is the same! Fig. B shows the bicompartmental group and Fig. A, dealing with the unicompartmental group, is very much the same, although the slope is flatter and more gradual.

DR. MOW AT It is interesting that the movement continues to improve and $I$ think that this has been our finding as well. Patients with early 'good' results may continue to show further improvement in the range of movement; they do not improve at first and then start to deteriorate. This is important, and means that this does not appear to be an 18-month or 2-year operation.

PROF. V. WRIGHT (Leeds) Dr. Mowat did not let us into the secret of how the assessments were made. I am interested to know whether the patients were assessed preoperatively and postoperatively by the same technique. We are engaged in a controlled trial of osteotomy and we find that it is most valuable to have a full assessment by the occupational therapist and another independent observer.

DR. MOW AT This was a retrospective survey, so that we did not have such complete preoperative data; this had to be culled from the notes and other available information.

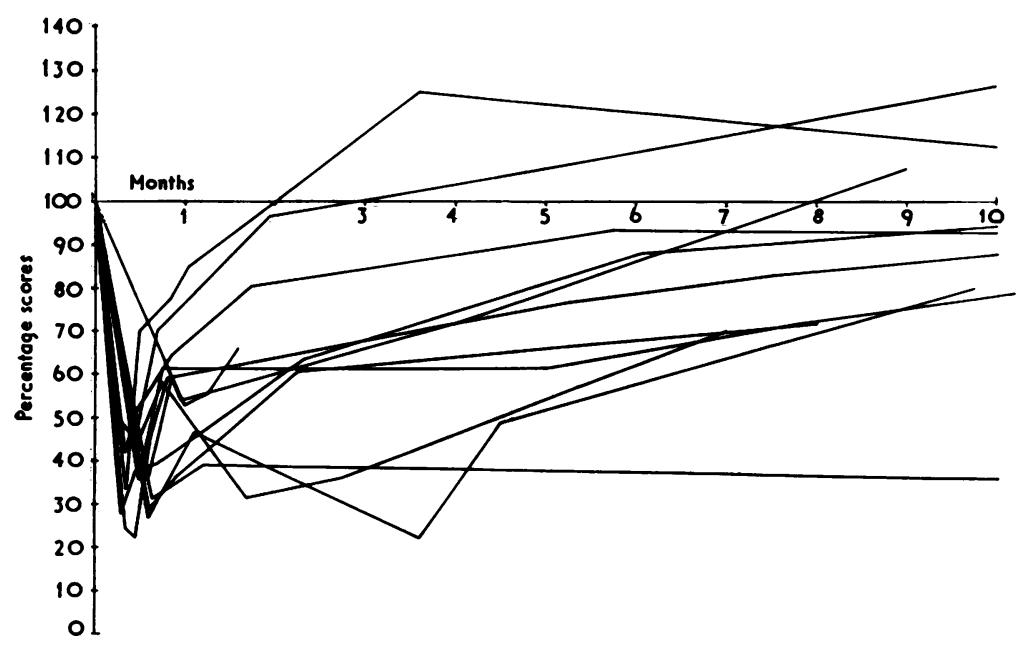

FIG. A Recovery of movement after unicompartmental surgery in eleven cases. Percentage scores for maximum flexion. 


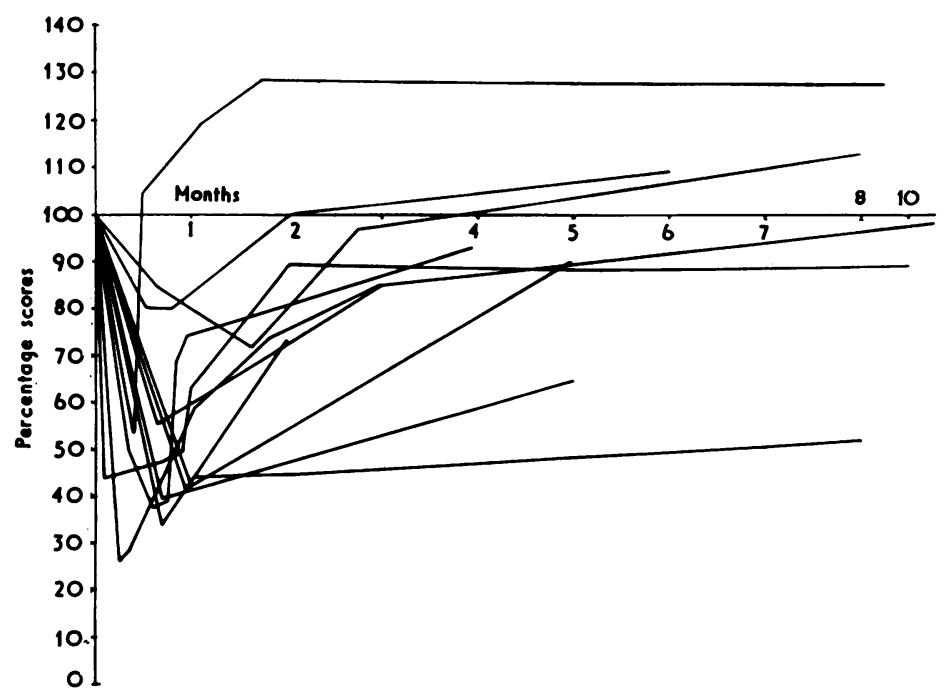

FIG. B Recovery of movement after bicompartmental surgery in eleven cases. Percentage scores for maximum flexion.

\section{References}

ANDERson, G. (1972) J. Bone Jt Surg., 54B, 621 (Hip assessment: a comparison of nine different methods)

ClARY, B. B., AND CouK, D. E. (1972) Sth. med.J., 65, 265 (Experience with the MacIntosh knee prosthesis)

Crellin, R. Q. (1965) J. Bone Jt Surg., 47B, 196 (MacIntosh prosthesis for tibial plateau fractures)

GarNer, R. W., Mowat, A. G., AND HaZleman, B. L. (1973) Ibid., 55B, 134 (Post-operative wound healing in patients with rheumatoid arthritis)

Henderson, E. D., AND Peterson, C. A. (1969) Sth. med.J., 62, 1311 (Experience with the use of the MacIntosh prosthesis in knees of patients with rheumatoid arthritis)

Jessop, J. D., AND MOORE, C. J. (1972) Rheum. phys. Med., 11, 217 (Follow-up of the MacIntosh arthroplasty of the knee joint)

KaY, N. R. M., AND MARTINS, H. D. (1972) J. Bone Jt Surg., 54B, 256 (The MacIntosh tibial plateau hemi-prosthesis for the rheumatoid knee)

LOWE, L. W., KATES, A., AND KAY, A. G. L. (1972) Ibid., 54B, 170 (MacIntosh arthroplasty in the rheumatoid knee)

McCollum, D. E., Goldner, J. L., AND LANG, S. N. (1970) Ibid., 52A, 827 (Tibial plateau prosthesis in arthroplasty of the knee)

MACINTOSH, D. L. (1966) Ibid., 48B, 179 (Arthroplasty of the knee in rheumatoid arthritis)

- AND HUNTER, G. A. (1972) Ibid., 54B, 244 (The use of the hemi arthroplasty prosthesis for advanced osteoarthritis and rheumatoid arthritis of the knee)

MURRAY, W. R. (1967) Ibid., 49A, 193 (Arthroplasty of the knee in rheumatoid arthritis)

PotTer, T. A. (1969) Surg. Clin. N. Amer., 49, 903 (Arthroplasty of the knee with a tibial metallic implant of the McKeever and MacIntosh design)

- - Weinfeld, M. S., AND Thomas, W. H. (1972) J. Bone Jt Surg., 54A, 1 (Arthroplasty of the knee in rheumatoid arthritis and osteoarthritis. A follow-up study after implantation of the McKeever and MacIntosh prostheses) 